\title{
FTIR analysis of chemical changes in wood induced by steaming and longitudinal compression
}

\author{
Mátyás Báder (1) • Róbert Németh (ib) Jakub Sandak (i) • Anna Sandak (D)
}

Received: 4 September 2019/Accepted: 31 March 2020/Published online: 29 May 2020

(C) The Author(s) 2020

\begin{abstract}
Pleating is an optimal way to increase bendability of wood used in diverse industrial applications. It results in the excessive buckling of cell walls and modifications of constitutive polymers. However, thoughtful understanding of the physicalchemical mechanisms of that modification process is very limited. The main purpose of the present study was to identify changes in functional groups of wood polymers induced by longitudinal compression. Four types of wood samples prepared from beech and sessile oak (untreated, steamed, longitudinally compressed and fixated for $1 \mathrm{~min}$ as well as longitudinally
\end{abstract}

\section{Báder $(\bowtie) \cdot$ R. Németh}

University of Sopron, Simonyi Károly Faculty of

Engineering, Wood Sciences and Applied Arts, Institute of Wood Science, 4 Bajcsy-Zs. Str., Sopron 9400, Hungary

e-mail: bader.matyas@uni-sopron.hu

J. Sandak · A. Sandak

InnoRenew CoE, Livade 6, Izola 6310, Slovenia compressed and fixated for $18 \mathrm{~h}$ ) were assessed by infrared spectroscopy. The spectra interpretation revealed that changes can be observed in hydroxyl as well as in carbon-oxygen single and carbon-hydrogen functional groups of polysaccharides and lignin. Beech wood seems to be more susceptible to investigated modification processes as compared to oak. Detailed interpretation of infrared spectra allows identification of changes in the hygroscopicity of wood as well as alterations in the linkage between structural elements in the polymer matrix of wood induced by the applied treatments.
J. Sandak

University of Primorska, Andrej Marusic Institute,

Koper 6000, Slovenia
A. Sandak
University of Primorska, Faculty of Mathematics, Natural Sciences and Information Technologies, Koper 6000, Slovenia 


\section{Graphic Abstract}

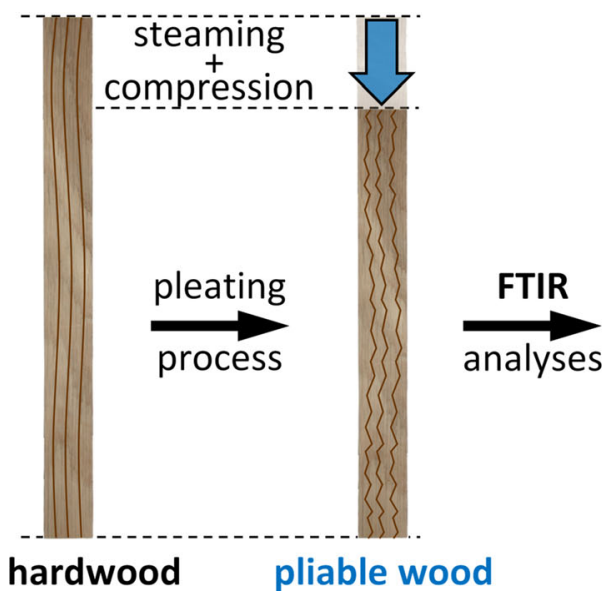

Keywords Infrared spectroscopy - Lignin · Hemicellulose Cellulose $\cdot$ Pleating process . Hygroscopic properties

\section{Introduction}

As described in earlier papers (Hanemann 1917; Stevens and Turner 1948; Vorreiter 1949; Báder and Németh 2017), the aim of longitudinal wood compression is to make the material pliable. The compression process results in excessive buckling of the cell wall, which allows much higher elongation without break during the proper wood bending. This process reduces the modulus of elasticity by 60 to $80 \%$ while the deflection of wood multiplies during bending tests (Kollmann 1951; Thomassen et al. 1990; Báder et al. 2019). Higher bendability is achieved after compression treatment by means of reduced forces necessary to deform the sample, comparing to untreated pieces or wood that was steamed and bent according to the traditional technology developed by Thonet (Báder and Németh 2018a). In addition to Thonet technology (curved parts of furniture), longitudinally compressed wood is used in interior design (wall coverings, coat hooks, handrails, etc.) as well as in individual applications (e.g., musical instruments, shoe insoles).

The initial step of modification by longitudinal compression is plasticization of wood in which the

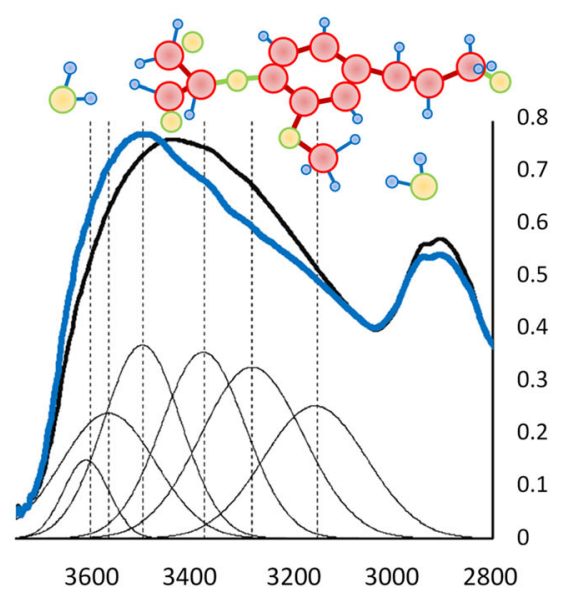

lignin and hemicelluloses pass their glass transition state. The minimum softening temperature of wood highly depends on its moisture content $M C$ (Lenth and Kamke 2001). In dry wood the temperature reaches $200{ }^{\circ} \mathrm{C}$ for both lignin and hemicelluloses. The glass transition temperature decreases till the fiber saturation point FSP and then the temperature remains relatively constant. It reaches approximately $80{ }^{\circ} \mathrm{C}$ for lignin in beech wood with $M C>35.6 \%$ or oak $>$ 24.5\% MC (Molnár 2004). Hemicelluloses pass their glass transition point already at room temperature if the moisture content exceeds FSP (Lenth and Kamke 2001).

Plasticization process is followed by the proper compression in a hot press. The elevated temperature and high relative humidity during compression assure that the processed wood is still in its plastic state while the sample is supported in order to not buckle and/or to break during pressing. Optionally, longitudinal wood compression can be followed by a fixation stage where the wood piece is detained in the compressed state for a period of time sufficient to cool down the material. This leads to relaxation of mechanical stresses as well as decreasing or preventing the spring-back effect. This process is known as pleating because of the buckled shape of cell walls after treatment (Báder et al. 2019). The intensity of fixation depends on its duration. It was noticed that wood loses approximately one third of its compression stress during the first minute of fixation (Báder et al. 2019). The compression stress still decreases after cooling down the piece 
(and crossing lignin glass transition temperature), even if the ratio of stress decrease is small.

Middle- or high- density hardwood species without knots, fiber deviations or any other deficiencies are optimal resources to be used for longitudinal compression treatment. Use of low-density wood results in the excessive collapse of its structure even at low compression ratios for the reason that constitutive cells are not strong enough to transmit the occurring compressive forces. The tissue of coniferous wood species is composed of thin-walled tracheal cells, which are inclined to micro-buckling of the material on the macroscopic level. It often results in fiber rupture and failure, rather than longitudinal compression (Báder and Németh 2018b). Wood is built up mainly ( $>99 \%$ ) of organic constituents, which can be divided into, on average, $49.5 \%$ () carbon, $44 \%$ oxygen, $6 \%$ hydrogen (mass\%) (Doalcis et al. 2002). The main chemical components (cellulose, hemicellulose and lignin) are built up from these constituents, and the cell walls are made up mainly of cellulose microfibrils embedded in a hemicellulose-lignin matrix (Poletto et al. 2010; Fahey et al. 2019). Cross-sectional variation in wood can be divided into the outer region with living parenchyma cells known as sapwood and the inner region with dead cells known as heartwood. Heartwood often, but not always, has darker color than sapwood due to its higher content of various extractive substances (Carballo-Meilan et al. 2014). This small amount of extractive materials consists of chromophoric groups (ethylene groups, carbonyl groups, benzene rings, orthoquinone, biaromatic rings, paraquinone, etc.) and auxochromic groups (hydroxyl groups, carboxyl groups, amino groups and ether groups) (Cao et al. 2012).

Beech and oak woods were selected for examination, because, as high-density deciduous species, these are suitable to compress in the longitudinal direction. Beech is a diffuse porous wood while oak is a ringporous with big vessels clogged by tyloses. Inclusion of both species in the experiment allows general investigation of main hardwood groups relevant from the commercial utilization perspective (Báder and Németh 2017). From a chemical point of view, both wood species are similar regarding overall cellulose, hemicelluloses and lignin contents (corresponding to approximately $45-42 \%, 23-25 \%$ and $24-25 \%$, respectively for beech-oak) (Pouwels et al. 1987; Jahnel 2000; Cortez et al. 1996; Szczepkowski et al.
2007; Wagenführ 2007; Bodîrlău et al. 2008; Fišerová et al. 2013; Sikora et al. 2018). However, beech contains less extractive substances $(0.6 \%)$ than oak $(3.0 \%)$. Even if the difference between total hemicellulose content of beech and oak is not remarkable (varying in the range of $\pm 1 \%$ ), the composition of matrix polysaccharides is very distinct. This difference, along with other mainly structural disparities, ensures much better weathering resistance of oak and its superior durability. However, its high extractives content leads to higher mass loss due to the thermal modification process in elevated temperatures, as was evidenced by several researchers (Ferrari et al. 2013; Costa et al. 2019).

Wood is a hygroscopic material; therefore, its properties are highly affected by the actual $M C$. The apparent changes of wood bulk are related to dimensional and shape variations as well as changes of mechanical properties when varying wood $M C$. The $M C$ of wood piece before longitudinal compression has to be high enough, preferably above the FSP, to assure the desired result of treatment. The average FSP value for wood in general is considered as $30 \%$ (Siau 1984; Niemz and Sonderegger 2017; Engelund et al. 2013). However, it can vary highly for individual wood species (e.g., guaiacum: 16.0\%, robinia: $19.5 \%$, oak: $24.5 \%$, beech: $35.6 \%$ or balsa: $63.7 \%$ ) (Molnár 2004). The water sorption in wood is a complex thermodynamic process related to polymer changes at the molecular level and can be assumed as a threestage process (Niemz and Sonderegger 2017). The first stage of sorption is between 0 and $6 \% M C$ where water molecules are linked by $\mathrm{H}$-bridge bonds to cellulose chains, forming a mono-molecular layer. The second stage occurs between 6 and 15\% MC when water molecules form a poly-molecular water layer that is not uniform on the whole surface and is connected by Van der Waals bonds or by electrostatic forces. In the $M C$ range from $15 \%$ to $F S P$, water vapor forms clusters in the intermicellar and interfibrillar cavities or condenses on the surface of the cell wall. The shrinkage/swelling of fibrils occur when absorbing/ releasing moisture in the whole range of relative humidity $(R H)$ (Engelund et al. 2013; Willems 2015).

The sorption sites correspond to functional groups of polymers attracting water molecules. Hydroxyl groups $(-\mathrm{OH})$ are the predominant sorption sites linking water with chemical components of wood by means of H-bonds (Engelund et al. 2013; Willems 
2018). Consequently, the available number of $-\mathrm{OH}$ (particularly in hemicelluloses) affects the thermodynamic mechanisms of sorption revealed as a change of wood $M C$ or other wood properties. As a whole, hemicelluloses possess the majority of sorption sites followed by cellulose and lignin. At the same time, hemicelluloses are polymers most vulnerable to chemical degradation when wood is exposed to elevated temperatures and consequently undergo thermal degradation more rapidly than cellulose (Schniewind 1989; Rowell et al. 2002; Sandak et al. 2016a, b). Low steaming temperature (max. $80^{\circ} \mathrm{C}$ ) causes mild reddish color change, but changes in the FTIR spectra are minor and difficult to observe. Detection of changes in the FTIR spectra is possible only by calculating ratios of relevant absorption peaks (Timar et al. 2016). More significant degradation of wood already occurs at a steaming temperature of $100{ }^{\circ} \mathrm{C}$. Some condensing compounds of lignin and hemicelluloses penetrate through the membranes of the pits in vessels, even after 10 min of plasticization (Mamonová et al. 2002), but still, no significant carbohydrate weight loss occurs (Schniewind 1989). Some strength reductions happen, which are due to depolymerization reactions (Schniewind 1989). There is a clear color change during steaming, which is attributed mostly to the extractives (Cao et al. 2012).

Plasticization or softening processes, which were in our case introduced by steaming at $100{ }^{\circ} \mathrm{C}$ using saturated water steam, mainly cause a weakening of the bonds of hemicelluloses and lignin, so the binding force both between cells and between microfibrils highly decreases (Báder and Németh 2017). Higher $M C$ decreases the softening temperature of amorphous polymers like hemicelluloses and lignin (Lenth and Kamke 2001). As an example, hemicelluloses soften even at room temperature around 70-75\% RH (Olsson and Salmén 2003; Engelund et al. 2013). Longitudinal compression treatment combined with wood plasticization and elevated temperatures results in a heavy rearrangement of molecules at the level of wood microstructure. Steaming temporarily breaks the bonds between lignin and hemicellulose and therefore for some extent transforms these constituents (Báder and Németh 2017). Compression is a mechanical wood modification process that causes changes between cells and within cells. For example, the originally straight microfibrils forming the $\mathrm{S} 2$ cell wall layer are bent (Báder et al. 2019). Subsequently, these processes essentially rearrange the wood structure at molecular, micro and macro levels. As a consequence, it is expected that the availability and configuration of sorption sites (functional groups) changes to diverse extents after wood plasticization, compression treatment and/or following fixation.

An assessment of the rearrangement of functional groups can be performed indirectly by means of vibrational spectroscopy. It was shown that infrared spectroscopy (IR) is a suitable technique to evince changes caused by diverse wood modification processes (Sandak et al. 2015; Sandak et al. 2016a, b). Part of the infrared radiation emitted to the measured surface is enhanced by the functional groups possessing a dipole momentum, which is recorded as an absorbance in the IR spectrum. The pattern of absorption is highly selective and depends on the molecular configuration of the measured polymer matrix as well as properties of the stimuli (radiation) applied (Sandak and Sandak 2018). IR spectrum is therefore a superposition of several absorption peaks that can be interpreted with band assessment tables published previously by several authors (Faix 1991; Schwanninger et al. 2004; Popescu et al. 2007; McLean et al. 2014; Guo et al. 2018; Moosavinejad et al. 2019).

Pleated wood has been industrially manufactured since the first half of the twentieth century, but thoughtful understanding of physical-chemical mechanisms of that modification process is still very limited. Thus, pleating is not a new topic but actually a barely studied field of wood modification. It was reported that Modulus of Rupture $(M o R)$ decreases after pleating process (20\% ratio) and fixation (1 min) between $21 \%$ for beech and $25 \%$ for oak (Báder and Németh 2018c). At the same time, the drop of Modulus of Elasticity $(\mathrm{MoE})$ reaches $60 \%$ for beech and $63 \%$ for oak. It corresponds to high increase of bendability varying from 380 to $440 \%$ for beech and oak, when compared to untreated samples of the same species. Bendability is at least 6 times higher for compressed wood fixated for an elongated time, compared to untreated samples. It was confirmed in the experimental tests performed by Báder and Németh (2018a), where wood samples were not broken even during excessive bending. Although the basic knowledge about the change of cellular structure was published over 70 years ago (Stevens and Turner 1948; Vorreiter 1949), the proper understanding of the 
pleating process is not known yet. Another underinvestigated topic is moisture-related behavior. For example, Báder and Németh (2017) have shown evidence that hygroscopicity of longitudinally compressed wood changes when compared to untreated wood, even if the detailed source of that alteration was unrevealed. Similarly, Báder and Németh (2019) published a study regarding the relationship of the mechanical properties and the $M C$ of pleated wood and found remarkable changes as a result of pleating. As an example, the change in modulus of elasticity with changing $M C$ was about three times higher compared to untreated wood. Knowledge regarding changes in $-\mathrm{OH}$ groups and other functional groups, being a result of the treatment, can provide explanation regarding broad moisture-related properties of wood, such as moisture content, sorption hysteresis, shrinkage, durability or service life performance. The goal of this research was, therefore, to fill the gap in missing knowledge and evince changes in the functional groups of wood induced by the pleating process.

\section{Materials and Methods}

\section{Sample preparation}

Four types of samples were prepared from both beech (Fagus sylvatica L.) and sessile oak (Quercus petraea
(Matt.) Liebl.) wood species by implementing following treatment procedures:

- Reference: the samples were untreated and only conditioned before characterization

- Steamed: the samples were steamed and conditioned, but not compressed

- Compressed and released: the samples were steamed, longitudinally compressed, fixated after compression for only $1 \mathrm{~min}$ and conditioned

- Compressed and fixated: the samples were steamed, longitudinally compressed followed by a fixation for a long period of $18 \mathrm{~h}$ and conditioned.

The raw material used for samples preparation originated from the forest of the Sopron region, Hungary. The material was preselected to include only pieces of heartwood from the same trunk, assuring straight grain orientation, consistent and uniform annual ring structure parallel to the sides and without knots or any other wood defects. At least two replicas for each sample type were prepared. The initial dimension of green samples was $20 \times 20 \times 200 \mathrm{~mm}^{3}$ (Radial $\times$ Tangential $\times$ Longitudinal, respectively). Each wood piece was cut in half along the RL direction to create two twin samples with dimensions of $20 \times 7 \times 200$ and $20 \times 10 \times 200(\mathrm{R} \times \mathrm{T} \times \mathrm{L}) \mathrm{mm}^{3}$ (Fig. 1). The first twin piece was considered as an untreated reference while the second was subjected to one of the modification processes listed above. Such a
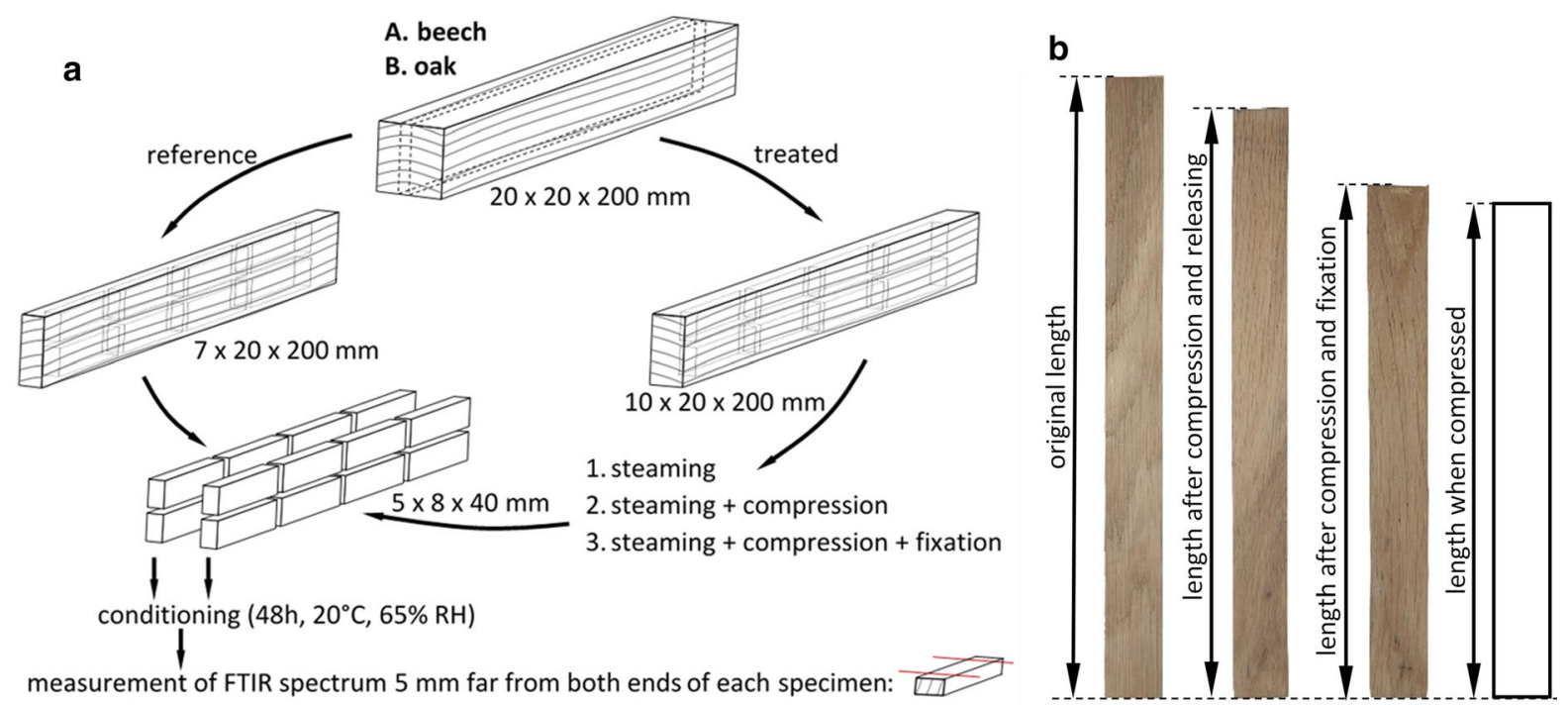

Fig. 1 Procedure for preparation of twin experimental specimens (a) and appearance of experimental oak samples (from left: reference/ steamed, compressed + released and compressed + fixated) (b) 
Table 1 Equilibrium moisture content of treated wood $(\%)$ at the time of FTIR measurements

\begin{tabular}{lllll}
\hline & Reference & Steamed & Compressed and released & Compressed and fixated \\
\hline Beech & $12.3(0.6)^{\mathrm{a}}$ & $12.5(0.1)^{\mathrm{b}}$ & $11.1(0.1)^{\mathrm{c}}$ & $11.8(0.1)^{\mathrm{d}}$ \\
Oak & $12.6(0.4)^{\mathrm{a}}$ & $12.5(0.1)^{\mathrm{a}}$ & $12.3(0.5)^{\mathrm{a}}$ & $12.3(0.3)^{\mathrm{b}}$ \\
\hline
\end{tabular}

Values in bracket correspond to standard deviation, superscript characters correspond to the statistically similar groups identified with post-hoc ANOVA $(\mathrm{p}<0.05)$

procedure of samples preparation allowed direct comparison of treatment effects with untreated samples, considering perfect matching of corresponding surfaces, therefore minimizing variability of results due to sample provenance and within tree variations.

All treated samples were plasticized for $1 \mathrm{~h}$ by steaming in a saturated steam at a temperature of $100{ }^{\circ} \mathrm{C}$. One third of these were taken apart and served as steamed samples. The remaining wood was longitudinally compressed with $20 \%$ compression ratio (relative to the sample length) in a custom-made accessory integrated with a universal material testing machine Instron 4208 (Instron Corp, USA). The compression velocity was $50 \mathrm{~mm} / \mathrm{min}$ and was performed with plasticized samples immediately after steaming. Half of the compressed samples (compressed and released) were kept fixated at their compressed state in the experimental stand for $1 \mathrm{~min}$ to allow natural relaxation of mechanical stresses induced by the treatment (Báder and Németh 2018a). The time of fixation was set in the control software of the used material testing machine. The other half of the samples (compressed and fixated) were kept compressed in the experimental stand for an additional $18 \mathrm{~h}$ after compression process. In that case, the wood sample cooled down in the semi-sealed chamber, minimizing moisture flow and, consequently, avoiding wood drying. All samples were conditioned (to constant mass) before further processing in a dark chamber at a temperature of $20{ }^{\circ} \mathrm{C}$ and $65 \% \mathrm{RH}$ to avoid photodegradation or any other post-process deterioration. The equilibrium moisture content $(E M C)$ of wood samples after different treatments is summarized in Table 1.

Small specimens were cut from the treated and reference wood samples to dimensions of $8 \times 5 \times 40$ $(\mathrm{R} \times \mathrm{T} \times \mathrm{L}) \mathrm{mm}^{3}$. Such a specimen size eased evaluation of the physical-chemical properties by means of the infrared spectroscopy. The cutting pattern was optimized to generate eight specimens for each replica (or six in the case of compressed and fixated). The scatter of infrared radiation from the measured surface is highly dependent on its smoothness (Tolvaj and Faix 1995); therefore, special care has been dedicated for proper specimens preparation. A sharp circular saw with high cutting and small feed speeds was used to avoid form deviations and minimize generated surface roughness. Each specimen was labeled with a unique code to allow tracing and referencing for further statistical analysis. The wood specimens were conditioned after processing for $48 \mathrm{~h}$ to uniform moisture distribution and surface oxidation state.

Statistical analysis was performed using Dell Statistica version 13 (Dell Inc, USA) software. A one-way analysis of variance (ANOVA) Fisher LSD test was used for comparative analyses of $M C$ for both reference and differently treated specimens. The differences were marked as significant at $\mathrm{p}<0.05$.

\section{FTIR measurement}

Infrared spectroscopy has been selected as an analytical method for assessment of physical-chemical changes to wood samples exposed to steaming and compression. The instrument used was a Jasco FT/IR 6300 Fourier Transform Infrared spectrophotometer (Jasco Inc, USA) equipped with a Diffuse Reflectance Infrared Fourier Transform (DRIFT) accessory, which illuminates the measured surface and, at the same time, collects the reflected light converting it into a spectrum. This technique is used for the characterization of solid samples or powders (both organic and inorganic) having a coarse surface, such as textiles, wood, bones or paper. Particle size, homogeneity and packing density of powdered samples highly influence the quality of spectrum; therefore, special attention should be directed to sample preparation and 
presentation (Sandak and Sandak 2018). In our case, the most important was to assure constant surface roughness in order to compare treatment effect. DRIFT spectra can result in an increase in resolution, compared to Attenuated Total Reflection (ATR) technique, but the results are influenced by the sample size differences, similar to the problems that occur during $\mathrm{KBr}$ pellet production (Beasley et al. 2014). Nevertheless, integration of sophisticated spectrometric measurements, such as a DRIFT spectroscopic technique, along with multivariate analysis method, is the most promising solution for characterization of ligno-cellulosic materials (Toivanen and Alén 2006).

Assessed specimens were presented to the instrument, assuring perpendicular wood fiber direction to the optical axis of the illuminating light. The longitudinal-radial surface of the wood was exposed to illuminating light in order to measure an average reflectance of the area covering several annual rings. The mid infrared spectral range included wavenumbers from 400 to $4000 \mathrm{~cm}^{-1}$, which corresponds to light wavelength from $25 \mu \mathrm{m}$ to $2500 \mathrm{~nm}$. The spectra were acquired in reflection mode with a resolution of $1 \mathrm{~cm}^{-1}$ and expressed as an absorbance. Sixteen consecutive spectra were averaged at each measurement point in order to increase signal-to-noise ratio. The surface of each specimen was measured $5 \mathrm{~mm}$ from both ends at the radial section. Therefore, 16 independent spectra were collected for each batch, separately for reference and treated twins. The only exception was compressed and fixated batches where only 6 specimens were cut due to excessive shortening of the original samples that remained as a result of the modification process. In total, 176 spectra for modified wood and 176 for twin references were collected in both wood species investigated.

All spectra were acquired by using Spectra Manager v.2.09.00 (Jasco Inc, USA) software and stored for further post-processing as text files on the computer disk. Background spectrum was obtained using the light trap while an aluminium sample holder was implemented for acquisition of the reference. All measurements were performed in a conditioned ambient temperature of $20^{\circ} \mathrm{C}$ and $50 \% R H$.

\section{FTIR analysis}

The infrared spectrum collected from the surface of wood in reflection mode is a superposition of light absorbance by functional groups of wood polymers (chemical information) and light scatter (physical information). Unfortunately, it is impossible to separate both signals from the spectrum as measured by DRIFT. Nevertheless, it is necessary to pre-process spectra before any systematic study and interpretation. The algorithm for data analysis as implemented in this research is summarized in Fig. 2. Both wood species (beech and oak) were separated at the initial stage in order to eliminate variability within the data due to species. Extended multiplicative scatter correction (EMSC) was applied here to minimize an effect of nonuniform optical density for measured wood specimens and related differences in the measured amplitude and baseline deviation (Gallagher et al. 2005). EMSC is a model-based pre-processing algorithm, capable to correct physical and chemical features in IR reflectance. It provides baseline correction and normalization as well as separation and quantification of chemical and physical variations in the vibrational spectra, making the subsequent calibration models simpler and statistically more robust (Panero et al. 2013). Although it loses some information, it estimates mathematical parameters instead, which can be used to study the different effects separately (Afseth and Kohler 2012). The specific settings of EMSC implemented in this research were: mean spectrum as a reference, order of polynomial $=2$, correction method by Classical Least Squares and T-squared limit $=0.99$.

Purposefully, no specific baseline correction was applied to the data at this stage of analysis to preserve original shape of the spectral curves and maintaining contributions of absorbance and scatter signals. Such adjusted spectra were then sorted into four classes according to treatment type and intensity. Principal components analysis (PCA\#1) was performed on that data set in order to identify clustering of specimens originated from different classes. In addition, ANOVA testing of the statistically significant differences between spectra collected from samples after different treatments was performed for oak and beech separately. As a result the grouping of spectra was evidenced and summarized in Table 2, assuming significant differences at $\mathrm{p}<0.05$. The software used was custom developed in LabView 2018 (National Instruments, USA) and Matlab (Mathworks, USA), by implementing a multiple comparison algorithm according to Bonferroni method. 


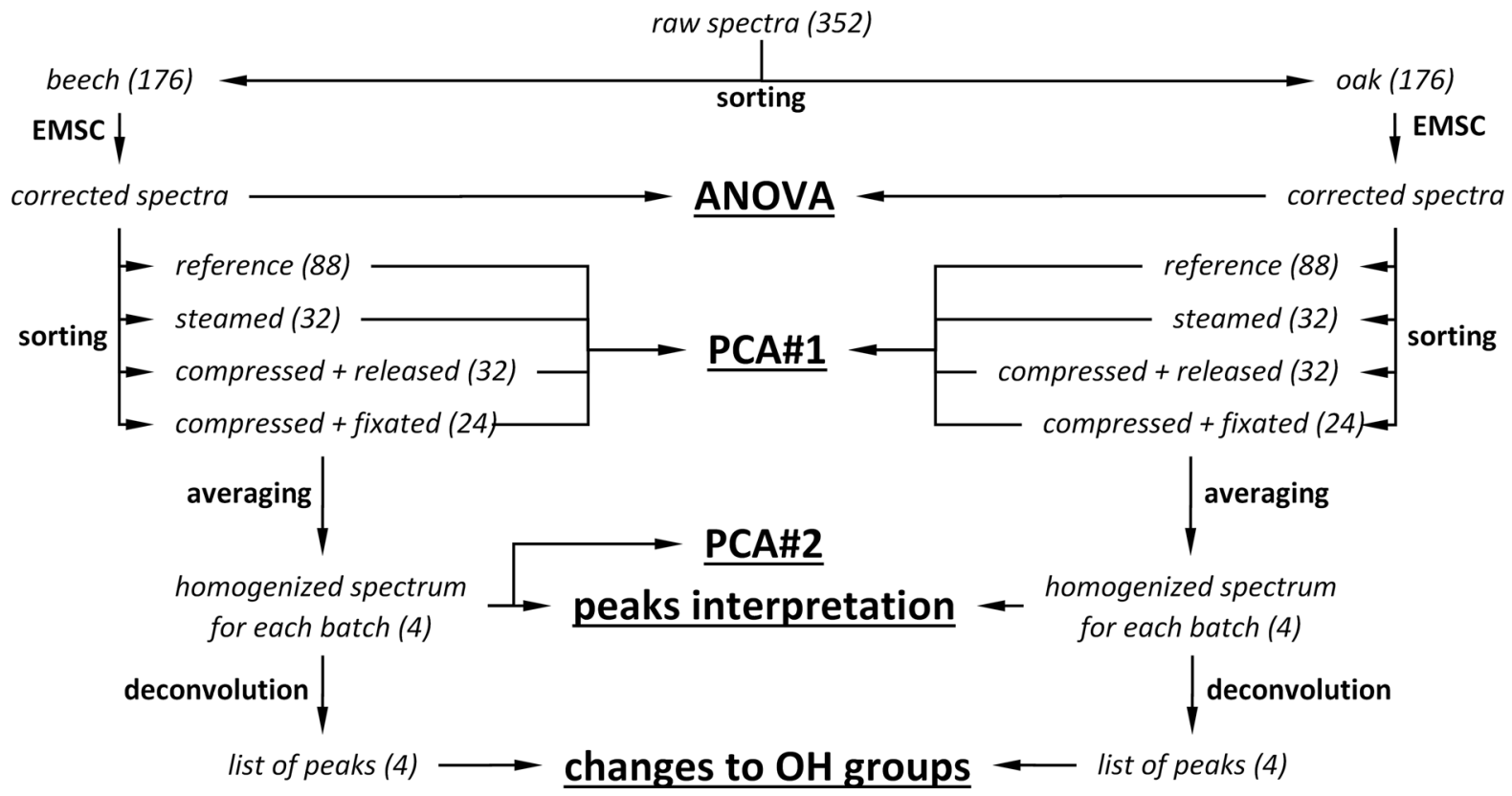

Fig. 2 Spectral data analysis of the thermo-hydro-mechanically modified wood. Note Digits in bracket correspond to the number of spectra/data available for analysis

Variability observed in the sorted spectra was still too high to perform direct spectra confrontation. For that reason, all spectra belonging to each batch (treatment class) were averaged to assure maximum homogenization and generalization of the spectral representation of specimens. Additional analysis (PCA\#2) was performed on that limited data set to highlight spectral features differentiating all classes. For that reason, PCA loadings were extracted and analyzed. The averaged spectra were also directly compared, and peaks interpretation was performed using literature references. Both variation of the amplitude and shift were visually assessed by the panel of experts separately for each peak, with all observations systematically summarized in Table 2 . The raw and pre-processed IR spectra of measured specimens can be found in https://doi.org/10.6084/m9. figshare.12024840 (Báder et al. 2020).

Part of the spectra (2800 to $3750 \mathrm{~cm}^{-1}$ ) corresponding to hydroxy functional groups $(-\mathrm{OH})$ was cropped from the averaged spectrum in order to deconvolve the spectra outline and list all peaks involved. Spectral deconvolution (or peak separation) is a method to identify peak composition in a complex spectrum, which is supposed to be a combination of multiple peaks. It is a case of IR spectroscopy where several broad and overlapping -OH peaks are located in a part of the spectrum scrutinized from the surface of wood. Shape of each peak was approximated as a Gaussian curve with the specified central position and full width at half maximum $(F W H M)$. A single baseline correction was applied to all spectra/batches before cropping, including quadratic polynomial fitting of the extreme (minimum) spectral points at 1028,1900 and $3812 \mathrm{~cm}^{-1}$. The deconvolution algorithm was optimized based on the probabilistic hybrid local search algorithm that was custom developed and implemented in LabView 2018 (National Instruments, USA) software. The custom algorithm identified an optimal set of peak locations, heights and widths, that were required to correctly reconstruct the original spectrum by superposition of convolved curves. The best software performance was achieved after providing initial guesses for all optimized variables. These were determined manually by following literature references. The objective of the software was to adjust these variables for each peak in the recurrent way, assuming minor but random variation of a single parameter at once. The loop was finalized after the RMS error of the difference between original and fitted outline of the spectrum was not reduced for at least 20 consecutive iterations. In that way it was 
Table 2 Band assignment and spectral peak changes in differently treated oak and beech wood

\begin{tabular}{|c|c|c|c|c|c|c|c|c|c|c|}
\hline \multirow[b]{2}{*}{ \# } & \multirow[b]{2}{*}{$\begin{array}{l}\text { peak } \\
\text { position }\end{array}$} & \multirow[b]{2}{*}{$\begin{array}{c}\text { literature } \\
\text { band } \\
\text { value }\end{array}$} & \multirow[b]{2}{*}{$\begin{array}{l}\text { refe- } \\
\text { rence }\end{array}$} & \multirow[b]{2}{*}{ band assignment } & \multicolumn{3}{|c|}{ beech } & \multicolumn{3}{|c|}{ oak } \\
\hline & & & & & steamed & \begin{tabular}{|c|} 
compres \\
sed \& \\
released
\end{tabular} & $\begin{array}{c}\text { compres } \\
\text { sed \& } \\
\text { fixated } \\
\end{array}$ & steamed & \begin{tabular}{|c|} 
compres \\
sed \& \\
released
\end{tabular} & \begin{tabular}{|c|} 
compres \\
sed \& \\
fixated \\
\end{tabular} \\
\hline 1 & 670 & 670 & [3] & $\mathrm{C}-\mathrm{OH}$ out of plane bending mode & $1 \mathrm{a}$ & $\mp \mathrm{b}$ & $1 \mathrm{~b}$ & $-b$ & $-b$ & I $c$ \\
\hline 2 & 834 & 834 & {$[1,8]$} & $\mathrm{C}-\mathrm{H}$ out-of-plane bonding in all positions of $\mathrm{H}$-units of lignin & $\boldsymbol{t} \mathrm{a}$ & 1 $\mathrm{b}$ & $\boldsymbol{1} \mathrm{b}$ & $-a$ & $-\mathrm{a}$ & $\boldsymbol{1} \mathrm{b}$ \\
\hline 3 & 897 & 897 & {$[10]$} & in-plane symmetric vibration of $\mathrm{C}-\mathrm{H}$ in cellulose & i a & $-a$ & $\mathrm{a}$ & $-a$ & $-a$ & $\boldsymbol{1} \mathrm{b}$ \\
\hline 4 & 996 & 985-996 & [5] & C-O valence vibrations & $5 \mathrm{a}$ & $F_{b}$ & $t_{b}$ & $-a$ & $\mathbf{F}_{\mathrm{b}}$ & $5 \mathrm{c}$ \\
\hline 5 & \multirow[t]{6}{*}{1044} & $1015-1060$ & [6] & C-O valence vibrations in cellulose & \multirow{6}{*}{$\mathbf{r}$} & \multirow{6}{*}{$\nabla$} & \multirow{6}{*}{$\nabla$} & \multirow{6}{*}{$\rightarrow$} & \multirow[b]{6}{*}{ b } & \multirow{6}{*}{$t$} \\
\hline & & 1033 & [1] & $\begin{array}{l}\text { aromatic C-H in-plane deformation, guaiacyl > syringyl; C-O } \\
\text { deform, in primary alcohols; } \mathrm{C}=\mathrm{O} \text { stretching (unconj.) }\end{array}$ & & & & & & \\
\hline & & 1034 & [6] & $\begin{array}{l}\text { symmetric stretching of C-O-C of acetyl groups, very weak band } \\
\text { in xyloglucan }\end{array}$ & & & & & & \\
\hline & & 1035 & [6] & $\mathrm{C}-\mathrm{O}$ stretching mainly of $\mathrm{C}_{6} \mathrm{H}_{2}-\mathrm{O}_{6} \mathrm{H}$ primary alcohols in cellulose & & & & & & \\
\hline & & 1041 & [6] & $\mathrm{C}-\mathrm{O}$ and $\mathrm{C}-\mathrm{C}$ ring changes in xyloglucan & & & & & & \\
\hline & & 1044 & [8] & C-O stretching in cellulose and non-cellulosic polysaccharides & & & & & & \\
\hline 6 & 1086 & 1086 & [5] & C-O deformation in secondary alcohols and aliphatic ethers & 5 a & $\checkmark b$ & $t_{\mathrm{b}}$ & $-b$ & $-a b$ & $\downarrow \mathrm{c}$ \\
\hline 7 & 1132 & 1139 & [8] & $\begin{array}{l}\text { aromatic C-H in-plane deformations in guaiacyl units, secondary } \\
\text { alcohols and C-O stretching }\end{array}$ & & & & & & \\
\hline & & 1126 & [1] & $\begin{array}{l}\text { guaiacyl condensed > etherified (typical for syringyl units); } \\
\text { secondary alcohols C-O stretching }\end{array}$ & L & L & L & $\dagger$ & 1 & 1 \\
\hline & & $1125-1162$ & [3] & C-O-C asymmetric valence vibrations & $\mathrm{ab}$ & b & a & $b$ & b & $\rightarrow$ \\
\hline 8 & 1174 & 1173 & [8] & C-O stretching in ester groups in lignin & $+\mathrm{b}$ & $+\mathrm{c}$ & $4 \mathrm{c}$ & i b & $1 \mathrm{~b}$ & t \\
\hline 9 & 1270 & 1269 & [8] & guaiacyl ring vibrations and C-O stretching lignin & & & & & & \\
\hline & & 1266 & [1] & guaiacyl ring vibrations and $\mathrm{C}-\mathrm{O}$ stretching lignin & $+a_{b}$ & $T_{b c}$ & $T_{c}$ & $\mathrm{~b}$ & b & a \\
\hline 10 & 1330 & 1330 & [10] & vibration in $\mathrm{C}-\mathrm{H}$ and stretching in $\mathrm{C}-\mathrm{O}$ related to syringyl ring & & & & & & \\
\hline & & 1329 & [1] & guaiacyl and syringyl ring condensation & $f \mathrm{~b}$ & f $c$ & $f_{b}$ & $f_{b}$ & $f^{\prime} \mathrm{b}$ & 7 \\
\hline 11 & 1378 & $1374-1378$ & {$[6,8]$} & $\mathrm{C}-\mathrm{H}$ bending in cellulose and non-cellulosic polysaccharides & & & & & & \\
\hline & & 1367 & [1] & aliphatic $\mathrm{C}-\mathrm{H}$ stretching in $\mathrm{CH}_{3}$ & b & $S_{c}$ & b & b & $\mathrm{b}$ & a \\
\hline 12 & 1428 & 1425 & {$[6,10]$} & $\begin{array}{l}\text { carboxylic acid and symmetric } \mathrm{COO} \text { - stretching; bending of } \mathrm{CH} \\
\text { groups in xyloglucan; vibration of aromatic structures in lignin }\end{array}$ & & & & & & \\
\hline & & 1422 & {$[1,6]$} & $\begin{array}{l}\text { vibration of aromatic structures in lignin; aromatic skeletal } \\
\text { combined with } \mathrm{C}-\mathrm{H} \text { in plane deformation }\end{array}$ & $\boldsymbol{1}$ & 1 & $\mathbf{1}$ & $\uparrow$ & 1 & - \\
\hline & & $1407-1428$ & [2] & bending of $\mathrm{CH}$ groups in cellulose & & & & & & \\
\hline & & 1430 & [6] & bending of $\mathrm{CH}_{2}$ groups in cellulose & b & c & bc & b & b & a \\
\hline 13 & 1458 & 1462 & {$[1,6]$} & $\mathrm{C}-\mathrm{H}$ deformations (asymmetric in $-\mathrm{CH}_{3}$ and in $-\mathrm{CH}_{2}$ ) & & & & & & \\
\hline & & 1460 & [6] & symmetric bending on pyran ring of $\mathrm{CH}_{2}$ groups in xyloglucan & & & & & & \\
\hline & & 1458 & [8] & $\begin{array}{l}\begin{array}{l}\text { aromatic skeletal vibrations of lignin and } \mathrm{CH}_{2} \text { vibrations in } \\
\text { cellulose }\end{array}\end{array}$ & 千 & 4 & $\uparrow$ & 1 & 1 & - \\
\hline & & 1455 & [6] & in plane bending of $\mathrm{OH}$ groups in cellulose & & & & & & \\
\hline & & $1447-1459$ & [2] & bending of $\mathrm{CH}_{3}$ in cellulose & $\mathrm{b}$ & c & $\mathrm{bc}$ & $b$ & $\mathrm{~b}$ & a \\
\hline 14 & 1505 & 1506 & [8] & aromatic skeletal vibrations and $\mathrm{C}=\mathrm{O}$ stretching of lignin & & & & & & \\
\hline & & 1505 & [1] & aromatic skeletal vibrations and $\mathrm{C}=\mathrm{O}$ stretching of lignin & $\mathbf{T}_{\mathrm{b}}$ & $\mathbf{T}_{\mathrm{b}}$ & $\mathrm{b}$ & $\mathrm{a}$ & $\mathrm{b}$ & $\mathrm{ab}$ \\
\hline 15 & 1598 & 1600 & [8] & aromatic skeletal vibrations of lignin and $\mathrm{C}=\mathrm{O}$ stretching & & & & & & \\
\hline & & 1594 & {$[1,9]$} & aromatic skeletal vibrations and $\mathrm{C}=\mathrm{O}$ stretching of lignin & $b$ & $1 \mathrm{~b}$ & ${ }_{a b}$ & ${ }^{-} a$ & $-a$ & $a^{a}$ \\
\hline 16 & 1652 & 1651 & [2] & bending of $\mathrm{HOH}$ groups; water of crystallinity & & & & & & \\
\hline & & 1654 & [10] & stretching vibrations of conjugated $\mathrm{C}=\mathrm{O}$ & $t$ & $t$ & $t$ & - & & \\
\hline & & 1658 & [1] & $\begin{array}{l}\mathrm{C}=0 \text { stretching; in conjugated } \mathrm{p} \text {-subst. aryl ketones; strong } \\
\text { electronegative substituents lower the wavenumber }\end{array}$ & & c & c & a & b & $a b$ \\
\hline 17 & 1740 & 1739 & [9] & $\begin{array}{l}\mathrm{C}=\mathrm{O} \text { stretching vibrations in the } \mathrm{O}=\mathrm{C}-\mathrm{OH} \text { group of the glucuronic } \\
\text { acid in xylan }\end{array}$ & & & & & & \\
\hline & & 1735 & [1] & $\begin{array}{l}\mathrm{C}=0 \text { stretching in unconjugated ketone, carbonyl and in ester } \\
\text { groups (frequently of carbohydrate origin); conjugated } \\
\text { aldehydes and carboxylic acids absorb around and below } 1700 \\
\mathrm{~cm}^{-1}\end{array}$ & $\mathcal{f}$ & $\downarrow$ & 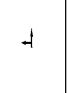 & 1 & - & 1 \\
\hline & & $1725-1745$ & [6] & $\mathrm{C}=\mathrm{O}$ stretching of acetyl or carboxylic acid groups in xyloglucan & b & $b$ & $\mathrm{ab}$ & b & $\mathrm{ab}$ & $\mathrm{b}$ \\
\hline 18 & 2902 & $2850-2940$ & [3] & symmetric $\mathrm{CH}_{2}$ valence vibrations & & & & & & \\
\hline & & $2862-2988$ & [2] & stretching of $\mathrm{C}-\mathrm{H}$ groups & + & $\checkmark b$ & b & 1 & $\therefore a$ & 1 \\
\hline 19 & 2940 & 2933 & [10] & $\begin{array}{l}\text { asymmetric stretching vibrations of } \mathrm{C}-\mathrm{H} \text { related to methyl and } \\
\text { methylene in lignin, cellulose and hemicellulose }\end{array}$ & & & & & & \\
\hline & & $2842-3000$ & [3] & $\mathrm{C}-\mathrm{H}$ stretching in methyl and methylene groups & $\downarrow$ & $\downarrow$ & $\downarrow$ & - & - & 1 \\
\hline & & $2840-3000$ & [1] & C-H stretching in methyl and methylene groups & $\mathrm{a}$ & b & b & a & $\mathrm{a}$ & $\mathrm{b}$ \\
\hline 20 & 3149 & 3149 & [9] & strongly $\mathrm{H}$-bonded water & & & & & & \\
\hline & & 3175 & [5] & $-\mathrm{OH}$ stretching intramolecular hydrogen bonds in cellulose & b & $\mathrm{b}$ & b & b & b & \\
\hline 21 & 3280 & 3277 & [7] & -OH intramolecular and intermolecular stretching modes & $\downarrow \mathrm{b}$ & $7 \mathrm{c}$ & I $\mathrm{c}$ & $-a$ & $-\mathrm{b}$ & $\downarrow$ \\
\hline 22 & 3375 & $3375-3340$ & [4] & $\mathrm{O}(3) \mathrm{H} . . \mathrm{O}(5)$ intramolecular hydrogen bonds in cellulose & $\downarrow \mathrm{b}$ & $7 \mathrm{c}$ & $\nabla \mathrm{c}$ & $-b$ & $-a b$ & $\downarrow$ \\
\hline 23 & 3496 & 3496 & [9] & moderately $\mathrm{H}$-bonded water & & & & & & \\
\hline & & $3450-3570$ & [3] & valence vibration of $\mathrm{H}$-bonded $\mathrm{OH}$ groups & $\mathrm{a}$ & $\mathbf{t} b$ & $\mathbf{t}_{\mathrm{b}}$ & a & b & 1 \\
\hline 24 & 3565 & $3580-3550$ & [4] & free $\mathrm{OH}(6)$ and $\mathrm{OH}(2)$, weakly absorbed water & $\boldsymbol{t} \mathrm{b}$ & $\boldsymbol{1} \mathrm{c}$ & $\boldsymbol{1} \mathrm{c}$ & $-a$ & $-b$ & $\mathbf{t}$ \\
\hline 25 & 3602 & 3602 & [9] & weakly $\mathrm{H}$-bonded water & i b & t c & $\uparrow \mathrm{c}$ & $-a$ & $-a$ & $1 b$ \\
\hline
\end{tabular}

Small letters correspond to the statistically similar groups identified with post-hoc ANOVA $(\mathrm{p}<0.05)$ with group "a" considered as reference. Trends of spectral changes are expressed with arrows $\|$ - low, $\mathbf{\uparrow} \downarrow$ medium (moderate), $\boldsymbol{\downarrow}-$ high. Arrows band shift. References: [1] Faix 1991; [2] Kacuráková et al. 1998; [3] Schwanninger et al. 2004; [4] Popescu et al. 2006; [5] Popescu et al. 2007; [6] Gierlinger et al. 2008; [7] Popescu et al. 2009; [8] McLean et al. 2014; [9] Guo et al. 2018; [10] Moosavinejad et al. 2019 
possible to compromise between optimization procedure (machine learning by software) and scientific foundations for the deconvolution of this complex spectral band. The change of area under the peak as well as its shift were considered as identifiers for treatment intensity. Root mean square difference between original and deconvolved spectra was used as the quantifier of deconvolution success as an alternative to the calculation of reduced chi-squared value for the deconvolved curves (Popescu et al. 2007; Donaldson et al. 2010).

The software used for spectra processing and analysis, including EMSC, averaging as well as PCA, was PLS_Toolbox (Eigenvector Inc, USA), available as an extension of the Matlab package (Mathworks, USA). Cross validation of the chemometric models was performed with the venetian blinds approach. In that method all source spectra are divided into $s$ splits of a given number $b$ of objects in each blind. The test set is determined by selecting every $s^{\text {th }}$ blind of spectra from the original dataset. The number of splits was $s=10$ with the blind width $b=1$. It has to be mentioned that the part of the spectrum ranging from 2600 to $1900 \mathrm{~cm}^{-1}$ was intentionally ignored as it does not contain any relevant spectroscopic information.

Band assignment and spectra interpretation

A great advantage of infrared spectroscopy is the possibility for direct interpretation of the spectrum as light absorbance is very selective for different molecules and functional groups present in wood. At the same time, wood is highly anisotropic and has a complex polymer matrix where different components interact with each other. Another critical factor is the high hygroscopicity of wood that tremendously affects its spectroscopic characterization. A lot of research efforts have been directed toward systematizing the infrared peaks interpretations that resulted in several scientific publications (Faix 1991; Schwanninger et al. 2004; Popescu et al. 2007, 2006, 2009; McLean et al. 2014; Guo et al. 2018; Moosavinejad et al. 2019). These papers were an inspiration to review the available know-how and adopt it for the specific needs of this research (thermo-hydro-mechanically treated hardwoods). The complete list of peaks observed in investigated experimental specimens is summarized in Table 2.

\section{Results and Discussion}

Equilibrium moisture content after treatments

EMC varied from $12.3 \%$ and $12.6 \%$ in the case of reference samples to $11.8 \%$ and $12.3 \%$ with compressed and fixated wood for beech and oak, respectively. Although the differences are small, the EMC of each sample group was altered by the thermo-hydromechanical treatments. Oak possessed most steady structure as its change in EMC was statistically significant only after compression treatment and fixation (Table 1). Changes of EMC in beech were significant already after the steaming process. Its cell lumens are not clogged with tyloses (as in oak) that easies washing effect induced by the steaming treatment.

An important difference between chemical content of beech and oak species lays in composition of hemicelluloses. The share of xylan extracted from hydrolysed beech wood is more than double of the same polymer extracted from oak, assuming the same mass loss. Xylose corresponds therefore to $77 \%$ of the total monosugars in beech, compare to $49 \%$ extracted from oak (Fišerová et al 2013). It was evidenced that xylan is the least stable polysaccharide when exposing various hemicelluloses (including P-glucan, arabinogalactan, arabinoxylan, galactomannan, glucomannan, xyloglucan, and xylan) to thermal decomposition in inert atmosphere (Werner et al. 2014). The variation of the hemicellulose composition in both species contributes even more to discrepancy of the steaming effects considered here as a mild thermal treatment of wood. Even if the total mass loss caused by this treatment is negligible, some chemical alteration of constitutive polymers (such as dehydratation, deacetylation, re-configuration, cross-linking) occurred. The hemicelluloses are the first structural compounds affected even at relatively low temperatures (Sandak and Sandak 2013). The degradation starts by deacetylation causing releasing of acetic acid. Acetic acid acts as a depolymerization catalyst, leading to further polysaccharide decomposition. Simultaneously hemicelluloses undergo dehydratation having effect in decrease of hydroxyl groups (Esteves and Pereira 2009). It will be evidenced below when discussing infrared reflectance spectra, that such chemical changes were more pronounced in beech 
than oak, confirming observations of changes noticed in EMC.

Compression resulted in the highest alterations in EMC of beech. It can be explained by variations in the number of available sorption sites (such as $-\mathrm{OH}$ groups) caused by the rearrangement of constitutive polymers due to mechanical action (extensive compression) in combination with the proceeding mild thermal treatment (steaming).

IR spectra interpretation in the fingerprint region $\left(1800-600 \mathrm{~cm}^{-1}\right)$

Figure 3 presents a set of averaged IR spectra collected from beech and oak wood specimens studied in this research (reference, steamed, compressed and released, compressed and fixated). Identified spectral bands are marked and numbered following the literature references as listed in Table 2. A summary of spectral analysis and interpretations induced by visual assessment are also summarized in the same table. Vertical arrows indicate the intensity of alterations (increase or decrease) while changes in the peak position (shifts) toward higher or lower wavenumber are represented by horizontal arrows. In all cases, treated wood spectra were compared to averaged untreated wood (reference) of the corresponding species.

Apparent differences between IR spectra of reference and modified woods are more pronounced in beech than oak, which indicates higher susceptibility of this species for chemical-physical changes induced by the pleating process. It was confirmed by ANOVA testing used for evidencing of the statistical differences between infrared absorbance induced by different treatments. Steaming seems to be a relatively mild process only slightly affecting chemical changes of the wood constitutive polymers. In the case of beech, changes in the functional groups induced by steaming are noticeable for several bands; however, the intensity of alterations is evidently lower than influence of compression and fixation treatments. The most noticeable peak drop as well as shift toward lower wavenumber, resulting from steaming processes, was noticed for band 4 (996) and 5 (1044) assigned to $\mathrm{C}-\mathrm{O}$ valence vibrations, $\mathrm{C}-\mathrm{O}$ stretching, $\mathrm{C}=\mathrm{O}$ stretching as well as to aromatic $\mathrm{C}-\mathrm{H}$ in-plane deformations. Lowered reflectance values signify the functional groups degradation (polysaccharides) and reduced cross-linking of lignin occurring in these particular bands.

Another drop in spectra reflectance can be observed in band 6 (1086), assigned to $\mathrm{C}-\mathrm{O}$ deformation in secondary alcohols and aliphatic ethers. Bands 18 (2902) and 19 (2940), linked with symmetric CH2 valence vibrations and asymmetric stretching vibrations of $\mathrm{CH}$ related to methyl and methylene in lignin, cellulose and hemicellulose, are also lowered but only after compression and compression followed by fixation. On the contrary, several IR bands exhibit increase of reflectance resulting from the modification processes. This is especially noticeable for bands 1 (670), 2 (834) and 8 to 14 (1147-1505). It can be associated to the condensation of lignin occurring after glass transition induced by elevated temperature in combination with mechanical stresses. Corresponding peaks in the IR spectra of oak wood do not exhibit pronounced visual differences. Moreover, some bands, in the case of oak, seem to not be affected at all by the thermo-hydro-mechanical (pleating) process (e.g., 15 (1598) and 16 (1652) being assigned to $\mathrm{C}=\mathrm{O}$ stretching and aromatic skeletal vibrations).

It has also been observed that noticeable deviations of IR spectra occurred in the range covering the hydroxy functional groups of wood polymers (peak 20 to 25 (3149-602)), which suggested changes of the hygroscopic properties of treated specimens. Dedicated analyses were therefore performed for these particular spectral bands that are reported in a subsequent chapter.

\section{Principal component analysis}

Principal component analysis (PCA) is a powerful chemometric method to reduce highly correlated and multi-dimensional data set to lower dimension. It searches for unique properties of spectral data and separates these into groups of peculiar similarities. Two PCA analysis were performed for the needs of this research. In the first, the whole range of spectra collected from measurements of singular specimens was analyzed, focusing on within batch variation (PCA\#1). The second analysis was performed on averaged spectra for each batch, providing a much more generalized spectroscopic description of the studied materials (PCA\#2). The data were mean centered before analysis by subtracting the average absorbance spectrum. This pre-processing is a routine 

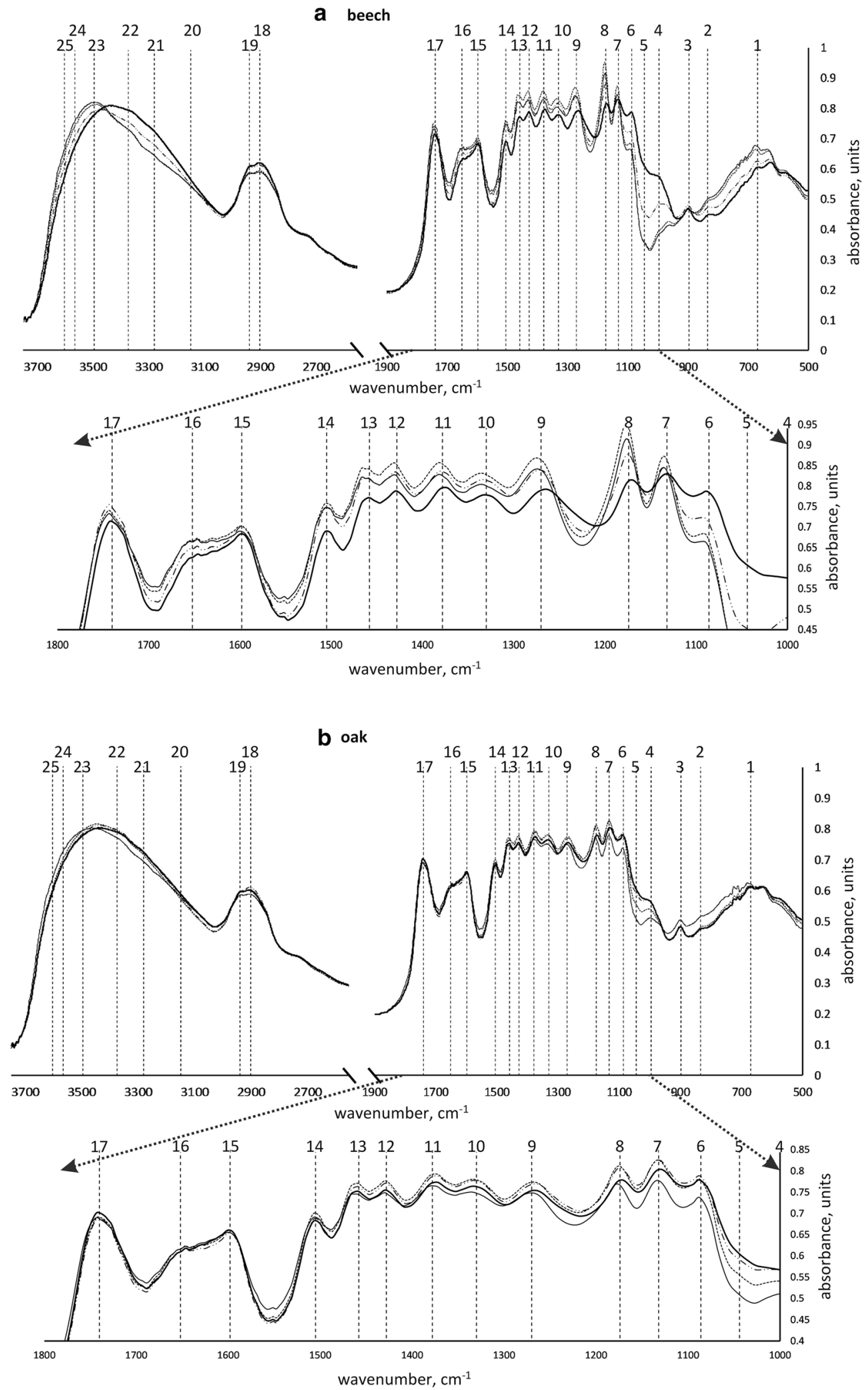
4Fig. 3 Infrared spectra of reference and differentlytreated beech (a) and oak (b) wood. Note Numbers correspond to identified peaks as summarized in Table 2

procedure performed before PCA computation to minimize the effect of a few dominating peaks on the overall chemometric model.

Results of PCA\#1 performed on the spectra of beech and oak wood are presented in Fig. 4. It is evident that treatment batches are better separated in the case of beech where a sequence from reference to compressed and fixated data points follow the PC1 axis direction. This component is dominant in the model and explains nearly $94 \%$ of the variance within data. The cluster of reference is clearly separated, confirming hypothesis of the profound effect of steaming and compression on the physical-chemical configuration of beech wood. The cluster of steamed wood slightly overlaps compressed samples and lays around the centre of the PC1. Both compressed sample types are partially overlapped, but some discrimination can be noticed when considering PC2 scores

The spectra corresponding to different batches of oak wood overlapped, creating a single cluster mixing reference, steamed and compressed specimens (Fig. 4). Only compressed and fixated spectra were, to some extent, detached from the rest, creating a separate cluster that slightly overlapped with compressed and released. The first principal component of PCA\#1 for oak explains almost $60 \%$ of variance while the second more than $20 \%$.

Additional analysis (PCA\#2) was performed on the averaged spectra of beech specimens. In that case, each batch was homogenized by computing the average value of absorbance for all wavenumbers, resulting in two data points per treatment type and six points for corresponding reference batches. The resulting score plot is presented in Fig. 5. Improved separability is evident compared to the cloud of data points shown in Fig. 4. Again, first principal component (PC1) separates the reference spectra from those modified, following treatment intensity. Steamed specimens are grouped in a single cluster, clearly separated from other treated woods by means of the second principal component (PC2). Averaged spectra collected from both compression treatments (released and fixated) overlap but, at the same time, are distant from the other clusters.

A great advantage of PCA is the possibility for identification of spectral features supporting discrimination. Two loadings corresponding to PC1 and PC2 are shown in Fig. 5, together with the reference position of identifiable spectral peaks (Table 2). First principal component discriminated reference
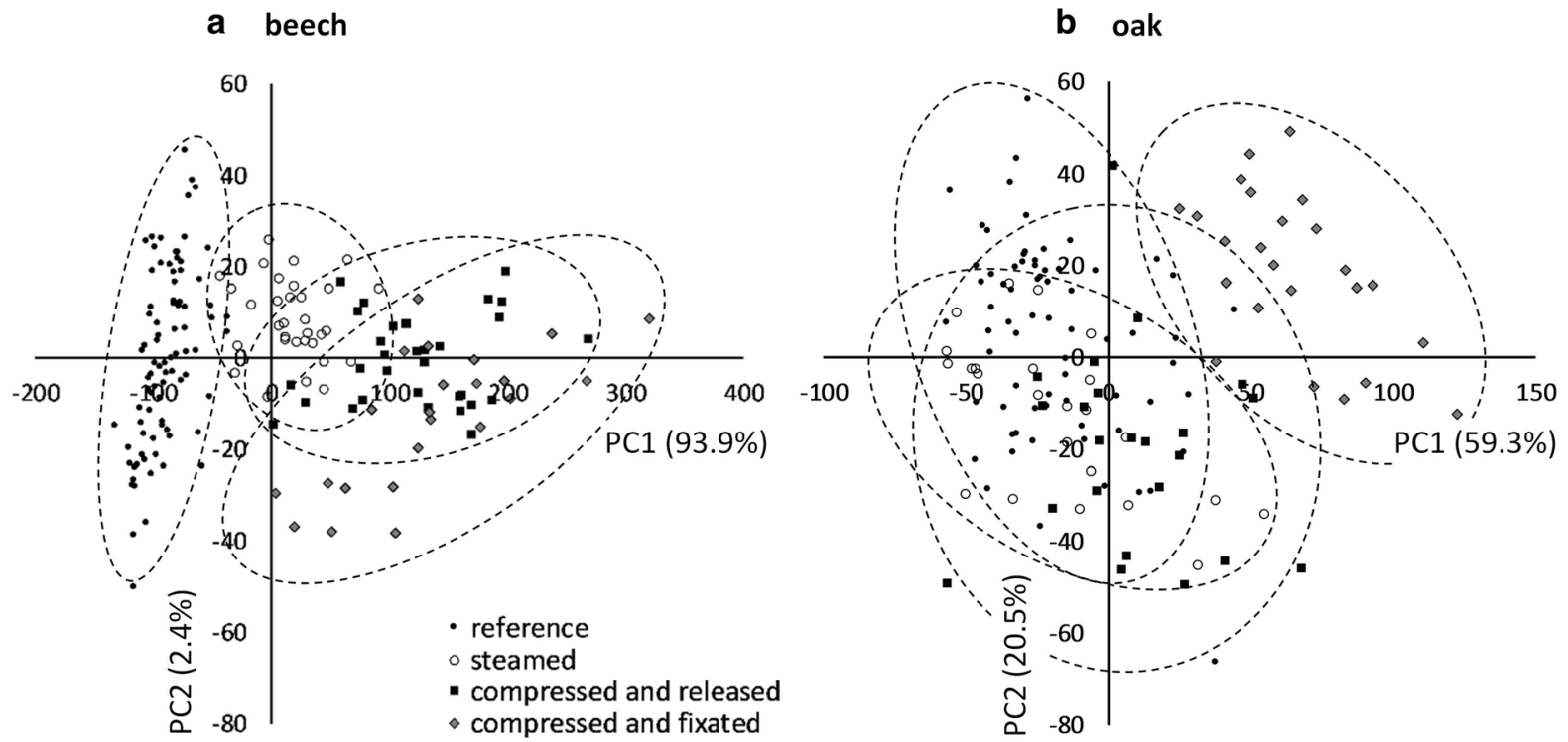

Fig. 4 Principal component analysis (PCA\#1) of beech (a) and oak (b) spectra corresponding to single measurements of experimental specimens. Note Fitting ellipses for confidence limits of $95 \%$ 
a

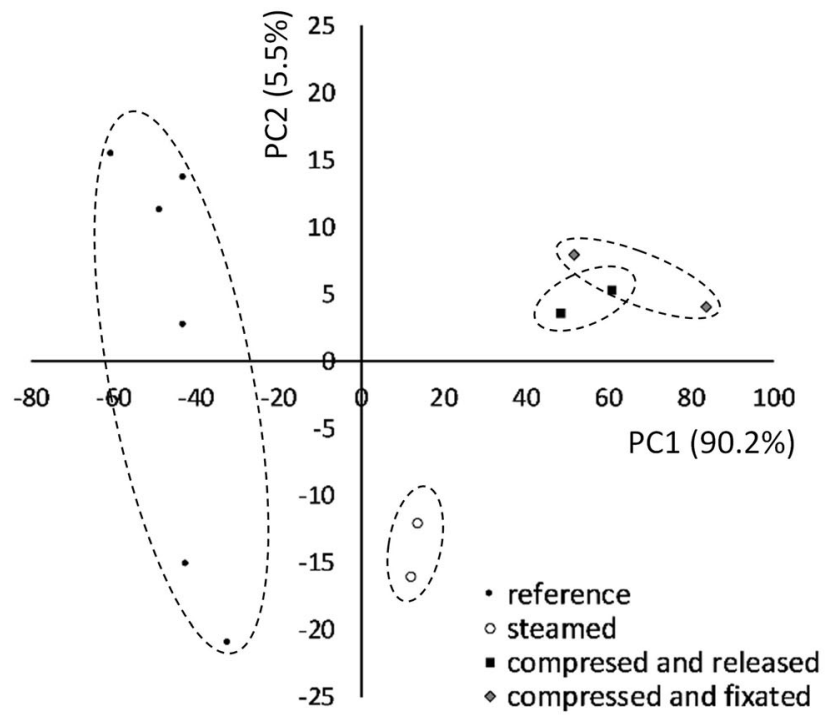

b

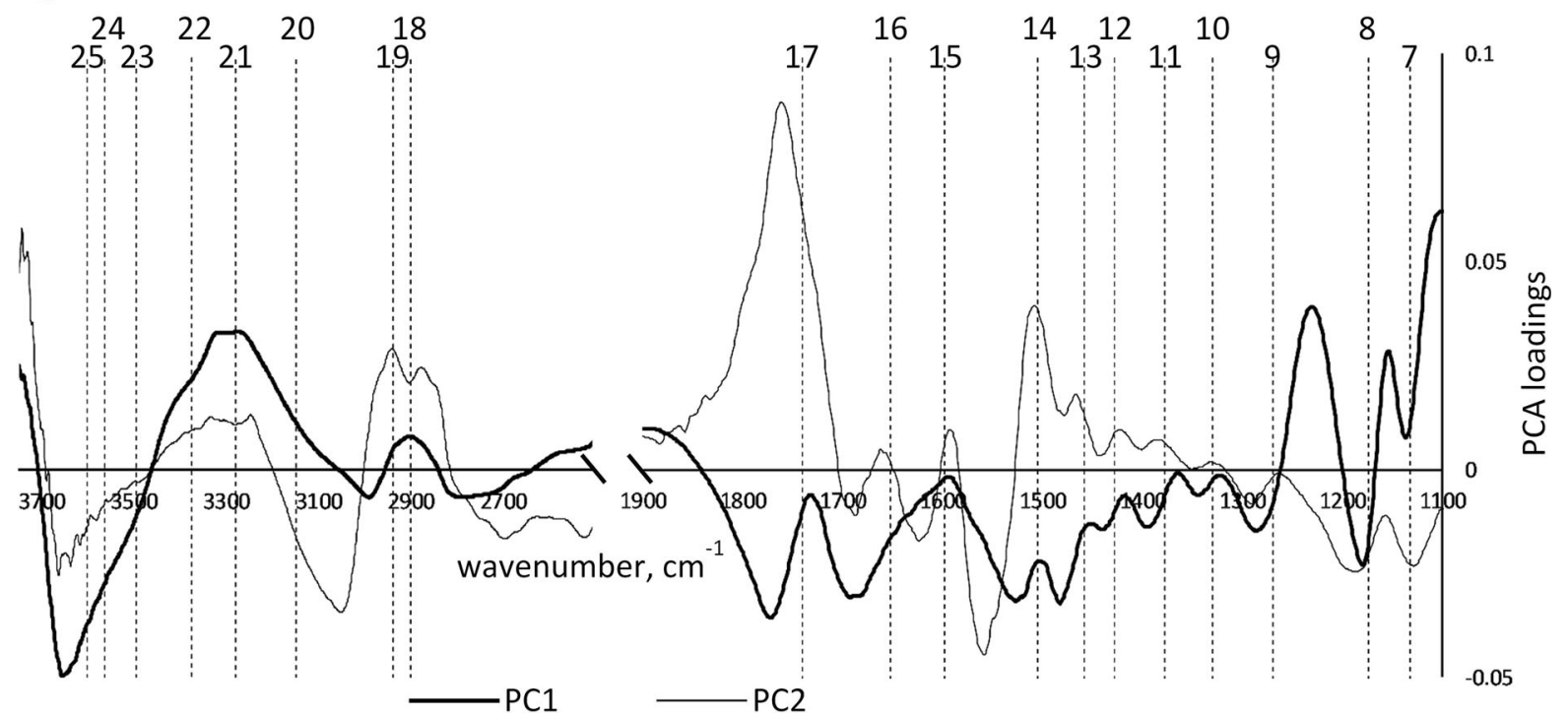

Fig. 5 Principal component analysis (PCA\#2) of averaged beech spectra corresponding to different treatments; PCA scores (a) and loadings (b)

(negative values) from all the treated samples (positive values). The most noteworthy peaks recorded in the corresponding loading are $8,9,13,14,16,17,21-25$ (1174, 1270, 1458, 1505, 1652, 1740, 3280-3602). It reveals that most affected polymers due to treatment are lignin $\left(\mathrm{C}-\mathrm{O}, \mathrm{C}=\mathrm{O}, \mathrm{CH}_{2}\right)$, cellulose $\left(\mathrm{CH}_{2}\right)$ and all hydroxyl groups affecting hygroscopic properties of wood. Low contribution of PC1 to the steamed wood spectra is related to moderately low absolute values of scores. It suggests the intermediate extent of changes, still indicating more similarity to compressed samples than to untreated wood (positive sign of scores). The second principal component allowed discrimination between steamed and compressed samples, where contribution of peaks 7, 8, 14, 17, 18, 19 (1132, 1174, 1505, 1740, 2902, 2940) are most dominant. It corresponds to the spectral changes particularly in lignin $\left(\mathrm{CH}, \mathrm{C}-\mathrm{O}, \mathrm{C}=\mathrm{O}, \mathrm{CH}_{2}\right)$, condensation of guaiacyl as well as in hemicellulose $(\mathrm{CH}, \mathrm{C}=\mathrm{O}$, $\mathrm{CH}_{2}$ ). Information recorded in both principal components corresponds to that interpreted by visual assessment with the exception of peak 17 (1740), possessing 
a high value in PC2 loading. However, the great importance of hydroxy groups (peaks 21 to 25 (3280-3602)) is evidenced, suggesting alteration of water sorption mechanisms in specimens after thermohydro-mechanical treatments.

As stated above, the extent of changes recorded in the FTIR of oak was much less profound than of beech. It was confirmed by PCA\#2 for oak (not reported here) where discrimination between clusters corresponding to different treatments was limited.

\section{Changes in hydroxy groups $\left(3700-3000 \mathrm{~cm}^{-1}\right)$}

Substantial changes to the FTIR spectra due to thermohydro-mechanical treatments are assigned to the modification of wood hygroscopic properties. Even if $E M C$ variation was not very high in specimens after conditioning (Table 1), many differences were statistically significant (ANOVA $\mathrm{p}<0.05$ ). Significant difference was detectable between all of the differently treated beech specimens and between oak reference and fixated specimens. Similarly, the outline of the IR spectra in the range corresponding to the absorbed water and -OH groups in general (3700 to $3000 \mathrm{~cm}^{-1}$ ) was evidently altered following intensity of treatment, especially in the case of beech (Fig. 3). A great limitation of the direct spectra interpretation in that range is presence of several peaks that are broad and highly overlapped. For that reason, a special software has been developed for deconvolution of spectral peaks, assuming that variations of the deconvoluted peak width and its maximum shift are restricted and controlled.

For the needs of this research, six -OH peaks were identified following literature references summarized in Table 2. Each of these are linked to different wood polymers and involved in uptake of moisture at different sorption stages. The result of compressed and fixated spectra deconvolution is shown in Fig. 6 for both beech and oak specimens. Areas and shifts for peaks of interest are plotted as a bar chart to highlight mechanisms of hygroscopic changes to the wood due to treatment. Even if the IR spectra outlines appear to be similar for both studied species, some slight differences are evidenced in the deconvolved peaks. The highest absorbances were noticed for peaks 21 (3280), 22 (3375) and 23 (3496) although the areas below these are rather constant and do not change due to treatments. On the contrary, peak at 24 (3565) (assigned to weakly absorbed water) decreases along treatment intensity. Such change is more monotonic in the case of oak than beech. The peak at 25 at $3602 \mathrm{~cm}^{-1}$ (weakly H-bonded water) follows the opposite trend and its area increases with treatment intensity. Variations of the peak area are associated to peak shifts. It is especially noticeable in the case of beech wood where three peaks (23 (3496), 24 (3565) and 25 (3602)) are monotonously shifted as related to the reference. This was not that evident in the case of more resistant (to the pleating process) oak wood.

The summary of above observations leads to the conclusion that absorbance of the hydroxyl functional groups associated to the weakly bonded wood increases noticeably following treatment intensity. On the contrary, the strongly bonded water is relatively stable and not affected by the treatment. It confirms the trend noticed with visual assessment of spectra (Table 2) as well as alterations of EMC.

It has to be mentioned that the thermo-hydromechanical treatment induces morphological changes to the wood that may affect the vapour transport within bulk (diffusion) and in the border of the wood and surrounding air (absorption). Even if it can not be directly evidenced by infrared spectroscopy, the water sorption sites availability changes also due to mechanical re-configuration of constitutive polymers (translocation and partial densification) in combination with micro/nano cracking of cell walls.

\section{Conclusions}

The objective of this research was to reveal chemical changes of two wood species induced by investigated thermo-hydro-mechanical treatment, which was an area not yet explored in this research field. Beech and oak wood samples at different stages of modification (untreated, steamed, compressed and fixated) were measured by Fourier-transform infrared spectroscopy with diffuse reflectance (DRIFT) technique. The spectra interpretation showed that changes can be observed in hydroxyl groups as well as in $\mathrm{C}-\mathrm{O}$ and $\mathrm{C}-$ $\mathrm{H}$ functional groups of polysaccharides and lignin. The principal component analysis on beech specimens showed good separation between batches. In the case of oak, only fixated specimens could be well separated from others. It proves that beech wood seems to be more susceptible to investigated THM modification 
a

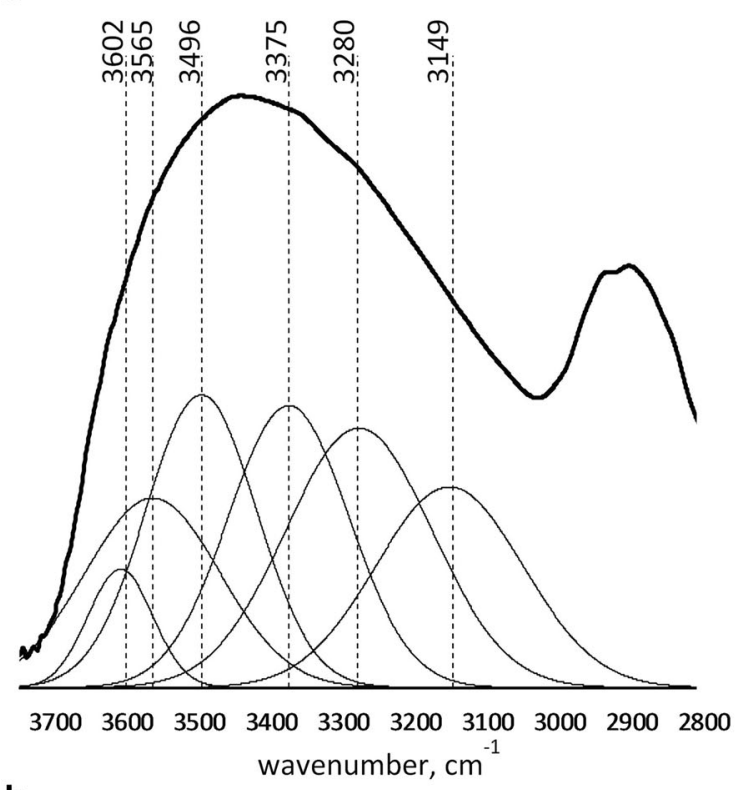

b

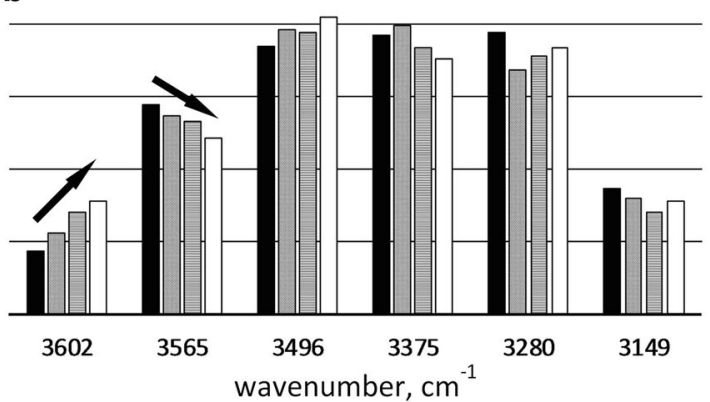

C

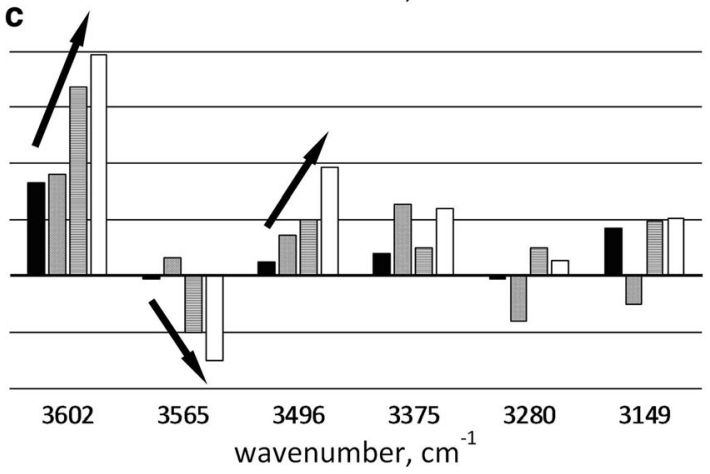

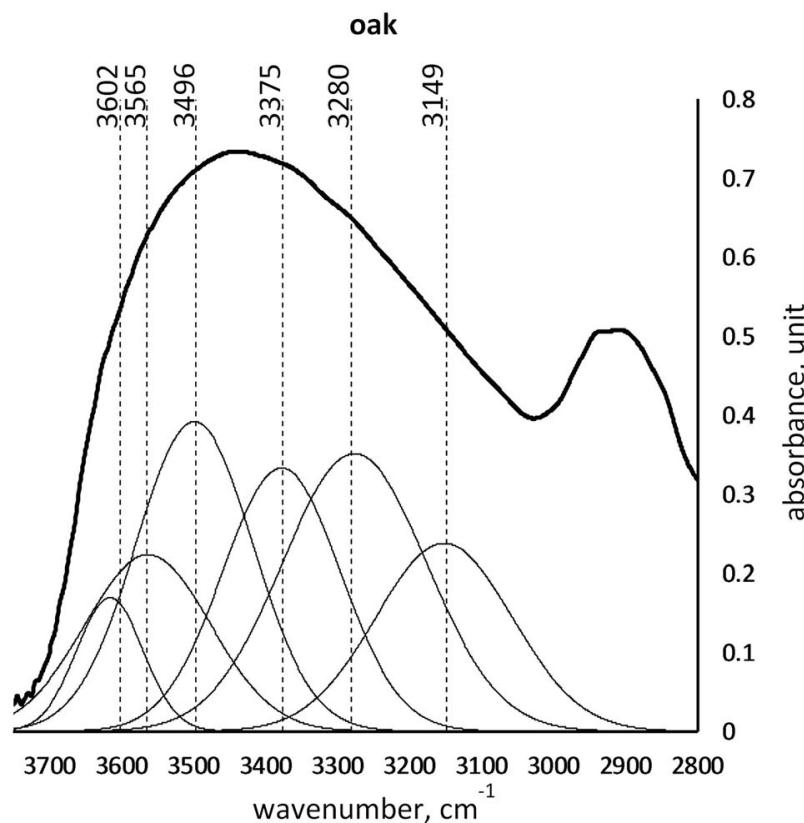

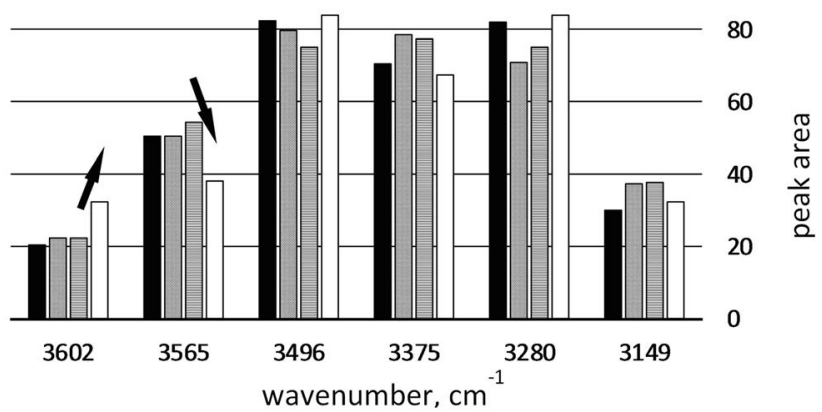

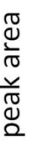

- reference $\square$ steamed $\quad \square$ compressed and released $\square$ compressed and fixated

Fig. 6 Deconvolution of reference specimens' spectra covering-OH groups present in wood (a), together with deconvolved peak area changes (b) and peak shifts (c) in case of beech (left) and oak (right) wood

processes as compared to oak. Deconvoluted spectra revealed changes in peak areas as well as band shift. Detailed interpretation of IR spectra allows identification of changes in the hygroscopicity of wood as well as changes in the linkage between structural elements in the polymer matrix of wood induced by the applied treatments. This study brings additional information to the knowledge of THM wood 
modification processes by providing explanation regarding behavior of functional groups of wood chemical constituents.

Acknowledgements Open access funding provided by University of Sopron (SOE). The study was published as part of the "Production with nature-Agroforestry as a new perspective", EFOP-3.6.2-16-2017-00018 project in the framework of the Széchenyi2020 Program. The realization of this project is supported by the European Union, co-financed by the European Social Fund. Mátyás Báder graciously thanks European Cooperation in Science and Technology (COST) Action FP1407 STSM (reference number: FP1407-43809) for the travel funding and support. The authors gratefully acknowledge the European Commission for funding the InnoRenew CoE project (Grant Agreement \#739574) under the Horizon2020 Widespread-Teaming program, the Republic of Slovenia (Investment funding of the Republic of Slovenia and the European Union of the European Regional Development Fund) and infrastructural ARRS program IO-0035. The authors would like to acknowledge the helpful advice regarding the measurements given by László Tolvaj and Miklós Bak, University of Sopron, Hungary. Special thanks to László Hajdu and Balázs Dávid for valuable suggestions on the deconvolution algorithm as well as to Liz Dickinson for English proofreading of this manuscript.

\section{Compliance with ethical standards}

Conflict of interest On behalf of all authors, the corresponding author states that there is no conflict of interest related to this manuscript.

Open Access This article is licensed under a Creative Commons Attribution 4.0 International License, which permits use, sharing, adaptation, distribution and reproduction in any medium or format, as long as you give appropriate credit to the original author(s) and the source, provide a link to the Creative Commons licence, and indicate if changes were made. The images or other third party material in this article are included in the article's Creative Commons licence, unless indicated otherwise in a credit line to the material. If material is not included in the article's Creative Commons licence and your intended use is not permitted by statutory regulation or exceeds the permitted use, you will need to obtain permission directly from the copyright holder. To view a copy of this licence, visit http://creativecommons.org/licenses/by/4.0/.

\section{References}

Afseth N, Kohler A (2012) Extended multiplicative signal correction in vibrational spectroscopy, a tutorial. Chemometr Intell Lab Syst 117:92-99. https://doi.org/10. 1016/j.chemolab.2012.03.004

Báder M, Németh R (2017) Hygroscopicity of longitudinally compressed wood. Acta Silv et Lignaria Hungarica 13:135-144. https://doi.org/10.1515/aslh-2017-0010
Báder M, Németh R (2018a) The effect of the relaxation time on the mechanical properties of longitudinally compressed wood. Wood Res 63:383-398

Báder M, Németh R (2018b) Production technology and properties of longitudinally compressed wood. In: Župčić I, Španić N (eds) Proceedings of the 29th International Conference on Wood Science and Technology. University of Zagreb-Faculty of Forestry, Zagreb, Croatia, pp 35-43

Báder M, Németh R (2018) The effect of the rate of longitudinal compression on selected wood properties. Acta Silv et Lignaria Hungarica 14:83-92. https://doi.org/10.2478/ aslh-2018-0005

Báder M, Németh R (2019) Moisture-dependent mechanical properties of longitudinally compressed wood. Eur J Wood Prod 77:1009-91019. https://doi.org/10.1007/s00107-01901448-1

Báder M, Németh R, Konnerth J (2019) Micromechanical properties of longitudinally compressed wood. Eur J Wood Prod 77:341-9351. https://doi.org/10.1007/s00107-01901392-0

Báder M, Németh R, Sandak J, Sandak A (2020) Resource 1: FTIR raw spectra of beech and oak specimens. Figshare LLP. https://doi.org/10.6084/m9.figshare.12024840

Beasley M, Bartelink E, Taylor L, Miller R (2014) Comparison of transmission FTIR, ATR, and DRIFT spectra: implications for assessment of bone bioapatite diagenesis. J Archaeol Sci 46:16-22. https://doi.org/10.1016/j.jas.2014.03. 008

Bodîrlău R, Teacă CA, Spiridon I (2008) Chemical modification of beech wood: effect on thermal stability. BioRes 3:789-800

Cao Y, Jiang J, Lu J et al (2012) Color change of Chinese fir through steam-heat treatment. BioRes 7:2809-2819

Carballo-Meilan A, Goodman A, Baron M, Gonzalez-Rodriguez J (2014) A specific case in the classification of woods by FTIR and chemometric: discrimination of Fagales from Malpighiales. Cellulose 21:261-273. https:// doi.org/10.1007/s10570-013-0093-2

Cortez J, Demard JM, Bottner P, Jocteur Monrozier L (1996) Decomposition of Mediterranean leaf litters: a microcosm experiment investigating relationships between decomposition rates and litter quality. Soil Biol Biochem 28:443-452

Costa JC, Branco JM, Camões A (2019) Thermal modification of most representative Portuguese wood species. A Prelima Study J Constr 18(3):488-500

Doalcis J, Tomsons E, Hrols J, Cirule D (2002) Dependence of heat value on moisture content for chips, sawdust pellets, and granules for different wood species. In: Kudela D, Kurjatko S (eds) Proceedings of the wood structure and properties '02. Arbora Publishers, Zvolen, Slovakia, pp 133-137

Donaldson L, Radotić K, Kalauzi A, Djikanović D, Jeremić M (2010) Quantification of compression wood severity in tracheids of Pinus radiata D. Don using confocal fluorescence imaging and spectral deconvolution. J of Struct Biol 169:106-115. https://doi.org/10.1016/j.jsb.2009.09.006

Engelund ET, Thygesen LG, Svensson S, Hill CAS (2013) A critical discussion of the physics of wood-water interactions. Wood Sci and Technol 47:141-161. https://doi.org/ 10.1007/s00226-012-0514-7 
Esteves B, Pereira H (2009) Wood modification by heat treatment: A review. BioRes 4:370-404

Fahey L, Nieuwoudt M, Harris P (2019) Predicting the cell-wall compositions of solid Pinus radiata (radiata pine) wood using NIR and ATR FTIR spectroscopies. Cellulose 26:7695-7716. https://doi.org/10.1007/s10570-019$02659-8$

Faix O (1991) Classification of lignins from different botanical origins by FT-IR spectroscopy. Holzforschung 45:21-27

Ferrari S, Cuccui I, Allegretti O (2013) Thermo-vacuum modification of some european softwood and hardwood species treated at different conditions. BioRes 8:1100-1109

Fišerová M, Opálená E, Illa A (2013) Comparative study of hemicelluloses extraction from beech and oak wood. Wood Res 58:543-554

Gallagher NB, Blake TA, Gassman PL (2005) Application of extended inverse scatter correction to mid-infrared reflectance spectra of soil. J Chemometr 19:271-281. https://doi. org/10.1002/cem.929

Gierlinger N, Goswami L, Schmidt M, Burgert I, Coutand C, Rogge T, Schwanninger M (2008) In situ FT-IR microscopic study on enzymatic treatment of poplar wood crosssections. Biomacromol 9:2194-2201

Guo X, Wu Y, Yan N (2018) In situ micro-FTIR observation of molecular association of adsorbed water with heat-treated wood. Wood Sci and Technol 52:971-985. https://doi.org/ 10.1007/s00226-018-1020-3

Hanemann M (1917) Wood treatment processes (Holzaufbereitungsverfahren). Patent Nr. 318197, Deutsches Reich Reichspatentamt

Jahnel F (2000) Manual of guitar technology. The Bold Summer Ltd, Westport, UK

Kacuráková M, Belton PS, Wilson RH, Hirsch J, Ebringerova A (1998) Hydration properties of xylan-type structures: an FTIR study of xylooligosaccharides. J Sci Food Agric 77:38-44

Kollmann FFP (1951) Technology of woods and wood materials. Springer-Verlag, Berlin Heidelberg, Germany

Lenth CA, Kamke FA (2001) Moisture dependent softening behavior of wood. Wood and Fiber Sci 33:492-507

Mamonová M, Laurová M, Nemcoková V (2002) Analysis of structure of beech wood subjected to hydrothermal treatment. In: Kudela D, Kurjatko S (eds) Proceedings of the wood structure and properties '02. Arbora Publishers, Zvolen, Slovakia, pp 51-55

McLean JP, Jin G, Brennan M et al (2014) Using NIR and ATRFTIR spectroscopy to rapidly detect compression wood in Pinus radiata. Canadian J of Forest Research 44:820-830. https://doi.org/10.1139/cjfr-2013-0329

Molnár S (2004) Wood material knowledge. Mezőgazdasági Szaktudás Kiadó, Budapest, Hungary

Moosavinejad SM, Madhoushi M, Vakili M, Rasouli D (2019) Evaluation of degradation in chemical compounds of wood in historical buildings using $\mathrm{ft}$-ir and ft-raman vibrational spectroscopy. Maderas: Ciencia y Tecnología 21:381-392. doi: 10.4067/S0718-221X2019005000310

Niemz P, Sonderegger WU (2017) Wood Physics: Physics of wood and wood-based materials. Fachbuchverlag Leipzig im Carl Hanser Verlag, München, Germany

Olsson A-M, Salmén L (2003) The softening behavior of hemicelluloses related to moisture. In: Gatenholm P,
Tenkanen M (eds) Hemicelluloses: science and technology. American Chemical Society, Washington, DC, pp 184-197

Panero P, Panero F, Panero J, Bezerra H (2013) Application of extended multiplicative signal correction to short-wavelength near infrared spectra of moisture in marzipan. J Data Anal Informat Process 1:30-34. https://doi.org/10.4236/ jdaip.2013.13005

Poletto M, Dettenborn J, Pistor V et al (2010) Materials produced from plant biomass. Part I: evaluation of thermal stability and pyrolysis of wood. Materials Res 13:375-379

Popescu C-M, Popescu M-C, Singurel G, Vasile C, Argyropoulos DS, Willför S (2007) Spectral characterization of eucalyptus wood. Appl Spectrosc 61:1168-1177

Popescu C-M, Singurel G, Popescu M-C, Vasile C, Argyropoulos DS, Willför S (2009) Vibrational spectroscopy and X-ray diffraction methods to establish the differences between hardwood and softwood. Carbohyd Polym 77:851-857. https://doi.org/10.1016/j.carbpol.2009.03. 011

Popescu C-M, Vasile C, Popescu M-C (2006) Degradation of lime wood painting supports II spectral characterisation. Cell Chem Technol 40:649-658

Pouwels AD, Tom A, Eijkel GB, Boon JJ (1987) Characterisation of beech wood and its holocellulose and xylan fractions by pyrolysis-gas chromatography-mass spectrometry. J Anal Appl Pyrolysis 11:417-436

Rowell R, Lange S, McSweeny J, Davis M (2002) Modification of wood fiber using steam. In: Humphrey P (ed) Proceedings of the 6th pacific rim bio-based composites symposium on the chemical modificaton of cellulosics. Portland, Oregon, USA, pp 606-615

Sandak A, Allegretti O, Cuccui I et al (2016) Thermo-vacuum modification of poplar veneers and its quality control. BioRes 11:10122-10139. https://doi.org/10.15376/biores. 11.4.10122-10139

Sandak A, Sandak J (2018) Infrared reflectance spectroscopy. In: López Varela S (ed) The encyclopedia of archaeological sciences. John Wiley \& Sons Inc, Hoboken, NJ, USA, pp 1-5

Sandak A, Sandak J, Allegretti O (2015) Quality control of vacuum thermally modified wood with near infrared spectroscopy. Vacuum 114:44-48. https://doi.org/10.1016/ j.vacuum.2014.12.027

Sandak J, Sandak A (2013) A method for verification of the heat sterilization according to ISPM-15. In Approfondimenti sull'aplicazione del trattamento temico (HT) secondo l'ISPM15 in Italia. Lampi di stampa, ISBN 978-88488-1395-2

Sandak J, Sandak A, Meder R (2016) Assessing trees, wood and derived products with near infrared spectroscopy: hints and tips. J Near Infrared Spectrosc 24:485-505. https://doi.org/ 10.1255/jnirs. 1255

Schniewind A (1989) Thermal degradation. In: Schniewind A (ed) Concise encyclopedia of wood \& wood-based materials, Pergamon Press. Elmsford, NY, USA, pp 271-273

Schwanninger M, Rodrigues J, Pereira H, Hinterstoisser B (2004) Effects of short-time vibratory ball milling on the shape of FT-IR spectra of wood and cellulose. Vib Spectrosc 36:23-40. https://doi.org/10.1016/j.vibspec.2004.02. 003 
Siau JF (1984) Transport processes in wood. Springer-Verlag, Berlin, Germany

Sikora A, Kačík F, Gaff M, Vondrová V, Bubeníková T, Kubovský I (2018) Impact of thermal modification on color and chemical changes of spruce and oak wood. J Wood Sci 64:406-416. https://doi.org/10.1007/s10086-018-1721-0

Stevens WC, Turner N (1948) Solid and laminated wood bending. His Majesty's Stationery Office, London, UK, Forest Products Research Laboratory, Department of Scientific and Industrial Research

Szczepkowski A, Nicewicz D, Koczon P (2007) The relationship between tree health and chemical composition of beech (Fagus sylvatica L.) and oak (Quercus robur L.) wood of Polish provenances. Acta Sci Pol 6:77-88

Thomassen T, Ljorring J, Hansen O (1990) A method and apparatus for compressing a wood sample. Patent $\mathrm{Nr}$. WO91/02637, World Intellectual Property Organization

Timar M, Varodi A, Hacibektasoglu M, Campean M (2016) Color and FTIR analysis of chemical changes in beech wood (Fagus sylvatica L.) after light streaming and heat treatment in two different environments. BioRes 11:8325-8343

Toivanen T, Alén R (2006) Variations in the chemical composition within pine (Pinus sylvestris) trunks determined by diffuse reflectance infrared spectroscopy and chemometrics. Cellulose 13:53-61. https://doi.org/10. 1007/s10570-005-9016-1

Tolvaj L, Faix O (1995) Artificial ageing of wood monitored by DRIFT spectroscopy and CIE L*a*b* color measurements I. Effect UV light. Holzforschung 49:397-404

Vorreiter L (1949) Woodtechnologycal handbook, vol I. Georg Fromme \& Co., Wien, Austria

Wagenführ R (2007) Holzatlas. Carl Hanser Verlag, München, Germany

Werner K, Pommer L, Broström M (2014) Thermal decomposition of hemicelluloses. J Anal Appl Pyrolysis 110:130-137

Willems W (2015) A critical review of the multilayer sorption models and comparison with the sorption site occupancy (SSO) model for wood moisture sorption isotherm analysis. Holzforschung 69:67-75. https://doi.org/10.1515/hf-20140069

Willems W (2018) Hygroscopic wood moisture: single and dimerized water molecules at hydroxyl-pair sites? Wood Sci Technol 52:777-791. https://doi.org/10.1007/s00226018-0998-x

Publisher's Note Springer Nature remains neutral with regard to jurisdictional claims in published maps and institutional affiliations. 